\title{
Prediction of the release process of the nitrogen-extinguishant binary mixture considering surface tension
}

\author{
Siyuan Liu ${ }^{a}$, Yongqi Xie ${ }^{a^{*}}$, Mengdong Chen ${ }^{b}$, Jianqin Zhu ${ }^{\mathfrak{c}^{* *}}$, Rodney Day ${ }^{\mathrm{d}}$, Hongwei Wu ${ }^{\mathrm{d}}$, Jianzu Yu${ }^{\mathrm{a}}$

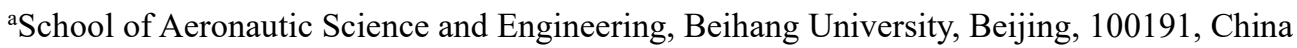 \\ ${ }^{\mathrm{b}}$ Global Energy Interconnection Research Institute, Beijing, 102200, China \\ ${ }^{c}$ National Key Laboratory of Science and Technology on Aero-Engines, School of Energy and Power \\ Engineering, Beihang University, Beijing 100191, China \\ ${ }^{\mathrm{d} S}$ School of Engineering and Computer Science, University of Hertfordshire, \\ Hatfield, AL10 9AB, United Kingdom
}

\begin{abstract}
Nitrogen used for pressurization in the extinguisher can be partially dissolved in the fire extinguishing agent. Consequently, the evolution of the dissolved nitrogen has a significant effect on the release behavior of the fire extinguishing agent in a rapid process. In this article, a new model was developed to predict the critical pressure of the nitrogen evolution and the release process of the fire extinguishing agent was described in detail. According to the PengRobinson (PR) equation of state and van der Waals mixing rule, the effect of the dissolved nitrogen on the surface tension of the fire extinguishant was analyzed by considering surface phase and fugacity coefficient. A method to calculate the surface tension of the liquid agent dissolved with nitrogen was proposed. The results showed that the proposed model can determine the accurate critical pressure of the evolution of the dissolved nitrogen and further evaluated whether nitrogen escapes. At different initial filling pressure, in addition, the release process of the nitrogen-extinguishant such as $\mathrm{CF}_{3} \mathrm{I}, \mathrm{FC} 218\left(\mathrm{C}_{3} \mathrm{~F}_{8}\right), \mathrm{HFC} 125\left(\mathrm{C}_{2} \mathrm{HF}_{5}\right)$, and Halon1301 $\left(\mathrm{CF}_{3} \mathrm{Br}\right)$ was well predicted by the fluid release model when taking the surface tension and adiabatic index of the mixture into account. Compared with the previously obtained experimental data, the predictions obtained indicated that the present model can adequately describe the liquid and the gas mixture release stage in the release process of the nitrogenextinguishant.
\end{abstract}

Keywords: gas-liquid equilibrium; equation of state; surface tension; homogeneous nucleation; escaping pressure; adiabatic index 
59 Superscripts

$60 \quad G$

Gas

61
$61 \quad L$
Liquid

\section{Subscripts}

Cohesive energy parameter in the PR equation of state, $\mathrm{Pa} \mathrm{m}^{6} \mathrm{~mol}^{-2}$

Surface area, $\mathrm{m}^{2}$; Constant defined in Eq. (9)

Volumetric parameter in the PR equation of state, $\mathrm{m}^{3} \mathrm{~mol}^{-1}$

Constant defined in Eq. (9)

fugacity, $\mathrm{Pa}$

Nucleation rate, nuclei $\mathrm{cm}^{-3} \mathrm{~s}^{-1}$

Binary interaction parameter

Molecular mass, $\mathrm{g}$

Avogadro constant, $6.02 \times 10^{23} \mathrm{~mol}^{-1}$

Pressure, $\mathrm{Pa}$

Bubble-point pressure, $\mathrm{Pa}$

Molar gas constant, $8.3145 \mathrm{~J} \mathrm{~mol}^{-1} \mathrm{~K}^{-1}$

Absolute temperature, $\mathrm{K}$

Initial temperature, $\mathrm{K}$

Molar volume, $\mathrm{m}^{3} / \mathrm{mol}$

Mole fraction

Mole fraction

Compressibility factor

Volume, $\mathrm{m}^{3}$

Function of temperature in the PR equation of state

Binary parameter

Function of the acentric factor

Fugacity coefficient

Acentric factor 


$\begin{array}{lll}63 & 1 & \text { Nitrogen } \\ 64 & 2 & \text { Agent } \\ 65 & \text { B } & \text { Bulk phase } \\ 66 & \mathrm{c} & \text { Critical point } \\ 67 & i, j & \text { Component identification } \\ 68 & \mathrm{~m} & \text { Mixture } \\ 69 & \mathrm{r} & \text { Reduced parameter } \\ 70 & \mathrm{~S} & \text { Surface phase } \\ 71 & \mathrm{~b} & \text { Bottle }\end{array}$

\section{Introduction}

Aircrafts may be confronted with the threat of fire. As an important subsystem of an aircraft, a fire suppression system equipped for an engine cabin can release sufficient fire extinguishing agent to put out a fire to guarantee safety. Nowadays, Halon1301 is normally utilized in military aircrafts since it is nontoxic and effective as fire extinguishing agent [1]. However, Halon1301 has been banned from production and utilization under Montreal Protocol which addresses global environmental concerns and the potential of high ozone depletion. Therefore, halon alternatives are being produced and used in recent years [2-4]. Grosshandler et al. [5] adopted $\mathrm{CF}_{3}$ I, FC218 and HFC125 to replace Halon1301 for the fire suppression in the dry bay. Saso et al. [6] examined the fire suppression effects of three kinds of hydrofluorocarbons (HFC) and perfluorocarbon (FC). Generally, these agents have low saturation vapor pressure at room temperature. In order to speed up the release of the agent, nitrogen is practically used as the pressurized medium in the extinguisher, which can ensure that the pressure is high enough inside and 4.2 MPa are always applied.

For the different initial filling pressure in the bottle, the pressure decay curve shows an obvious difference in the process of releasing Halon1301 [7-9]. For a low filling pressure, nitrogen dissolved in the liquid agent cannot escape in the process of the releasing extinguishing agent. Under this condition, the release process was approximately divided into two stages by Elliott [7] and Yang [8, 9]. However, when the filling pressure is high, the nitrogen dissolved in the liquid agent will come out of the liquid along with a rapid pressure drop in the bottle, which 
has been verified by the rapid release test of agent. As the total pressure in bottle is lower than the nucleation pressure of the dissolved nitrogen, the nitrogen is released in the form of bubbles from the liquid agent. This will lead to the short-term increase of the pressure in the bottle. Typical pressure-time curves during the low-pressure release and high-pressure release were presented by Yang et al. [9].

Experimental investigation on the pressure variation during the release of Halon1301 was performed by Elliott et al. [7], when the initial filling pressure was varied from 4.48 $\mathrm{MPa}$ to 10.24 MPa and the initial filling temperature was increased from $12{ }^{\circ} \mathrm{C}$ to $63{ }^{\circ} \mathrm{C}$, accordingly. However, the critical pressure of the nitrogen evolution was not addressed theoretically. It was only assumed that the total pressure in the escaping bubble was the same as the filling pressure and decreased slowly with the drop of the temperature. Moreover, they also believed that the surface tension of Halon1301 had an important effect on the nitrogen escaping pressure. But they did not take the effect of the dissolved nitrogen on the surface tension of Halon1301 into account.

During the release of the extinguishing agent, the dissolved nitrogen may escape and lead to the pressure rise inside the bottle. Elliot et al. [7] studied the Halon1301 release process and assumed that the critical radius of nitrogen escaping bubble was $7.5 \mathrm{~nm}$, which has been adopted by HFLOW software. According to the homogeneous nucleation theory, Blander et al. [10] and Forest et al. [11] developed a mathematical model describing the homogeneous nucleation process of bubble in solution. They further validated the model against the experiments for nitrogen dissolved in aether. Yang et al. [9] developed a model to calculate the critical pressure of the nitrogen escape for Halon1301, HFC125, FC218 and $\mathrm{CF}_{3} \mathrm{I}$, which can accurately determine whether nitrogen escape occurs during the release of agent. However, their model can only be used to qualitatively explain the variation of nitrogen escaping pressure. In recent years, some researchers $[12,13]$ calculated the critical bubble size in the process of gas-phase in binary systems through the modified Gibbs' approach, which provided new insights for analyzing the critical radius of the nitrogen escaping bubbles.

The determination of the surface tension of the mixture of dissolved nitrogen and liquid agent is involved in the study of the critical state of nitrogen escaping. As for the calculation of the surface tension for pure liquid agent, the method based on the principle of corresponding state and parachor was recognized as the most accurate. For instance, Jiang et al. [14] used a piecewise function method to define the surface tension of the liquid $\mathrm{CO}_{2}$ based on the Parachor 
Macleod-Sugden correlation and Brock-Bird correlation. Duan et al. [15] developed a prediction method of surface tension for twenty types of HFCs and HCFCs based on the principle of corresponding state. Nicola and Moglie $[16,17]$ also presented a similar prediction method for the surface tension of total 28 refrigerants with that developed by Duan et al. [15], such as HFC 227ea, FC218, HFC125 and Halon1301. If combined with a suitable mixing rule, van der Waals equation could also be used to calculate the surface tension of multicomponent HFCs mixtures [18, 19]. Additionally, Carey et al. [20] firstly combined the density gradient theory with the cubic equation of state to determine the surface tension of pure fluid, which expanded the application scope of density gradient theory [21, 22]. In terms of the measurement of the surface tension, recently, Wang [23] studied the surface tension of the organosilicone surfactant as foam extinguishing agent by orthogonal experiments, while Baidakov et al. [2426] tested the surface tension of the mixed solutions of nitrogen-methane, nitrogen-ethane and methane-ethane in the temperature ranging from $95 \mathrm{~K}$ to $170 \mathrm{~K}, 93 \mathrm{~K}$ to $283 \mathrm{~K}$ and $93 \mathrm{~K}$ to 283 $\mathrm{K}$, respectively.

Dinenno et al. [27] and Yang et al. [3, 28] proposed mathematical models to analyze the release process of the fire extinguishing agent in bottles. The former assumed that the average release flow in any time step was consistent with the flow when the fluid in the fire extinguisher was stable; while the latter assumed that the gas mixture drove the liquid fire extinguishing agent like a piston during the release process as an adiabatic reversible isentropic process, ignoring the effect of the extinguishing agent vapor.

It is significant to accurately determine the specific heat capacity at constant pressure in the calculation of the adiabatic index of actual gas mixture. The thermodynamic properties of fluids can be calculated according to the Maxwell function and the cofunction method. Lemmon and Jacobsen $[29,30]$ calculated the thermodynamic properties including specific heat capacity at constant pressure of various refrigerants and their mixtures based on Helmholtz free energy equation, but the coefficients of the equation were too many to be convenient to use. He et al. [31] chose PR equation combined with van der Waals mixing rule and $81 \mathrm{M}-\mathrm{H}$ equation combined with constant mixing rule to establish a calculation model which can accurately predict the specific heat capacity at constant pressure of pure HFC227ea and pure HFC125.

To the best of author's knowledge, there are no detailed researches available in the open 
literature regarding the effect of the dissolved nitrogen on the surface tension of the liquid fire extinguishing agent and the mathematic model predicting the critical pressure for the evolution of dissolved nitrogen. Therefore, the current work aims to develop a method to calculate the surface tension of the liquid agent dissolved with nitrogen, and further describe the release process of the mixture of nitrogen and fire extinguishing agent. PR equation of state and van der Waals mixing rule are selected and the effect of the dissolved nitrogen on the surface tension of liquid extinguishing agent taking Halon1301 as an example is analyzed and discussed based on the corresponding thermodynamic model. Another major contribution of the current work is to develop a fluid release model in order to predict the release process of the mixture of nitrogen and fire extinguishing agent, such as $\mathrm{CF}_{3} \mathrm{I}, \mathrm{FC} 218\left(\mathrm{C}_{3} \mathrm{~F}_{8}\right), \mathrm{HFC} 125\left(\mathrm{C}_{2} \mathrm{HF}_{5}\right)$, and Halon1301 $\left(\mathrm{CF}_{3} \mathrm{Br}\right)$. The homogeneous nucleation theory is used and a constant critical radius of nitrogen evolution under different filling conditions is assumed, to determine the critical pressure of the nitrogen evolution in the fire extinguisher. Furthermore, based on the state equation and mixing rules, the adiabatic index of the mixture of nitrogen and fire extinguishing agent steam are calculated accurately. According to the actual adiabatic isentropic expansion process of gas, the differential equation of the fluid release process in the fire extinguisher is derived. The fourthorder Runge Kutta method is applied to solve the equation, which can predict the whole release process of various mixtures of nitrogen-extinguishant.

\section{Surface tension of mixture}

During the release of the fire extinguishing agent, the surface tension of the liquid agent dissolved with nitrogen has an important impact on nitrogen evolution. As the binary system of nitrogen-extinguishant reaches gas-liquid equilibrium, the surface phase occurs between the gas phase and liquid phase. The components inside the surface phase are considered as constant and uniform distribution. Based on the theoretical model of surface tension, the thermodynamic correlation predicting the surface tension of mixture can be obtained by defining the fugacity of surface phase and fugacity coefficient, and considering the relationship, among surface tension, chemical potential and fugacity [32], as described in the equation below.

$$
\sigma_{\mathrm{m}}=\frac{A_{i}}{\overline{A_{i}}} \sigma_{i}+\frac{R T}{\overline{A_{i}}} \ln \frac{\varphi_{i \mathrm{~S}} y_{i \mathrm{~S}}}{\varphi_{i \mathrm{~B}} y_{i \mathrm{~B}}}
$$


where $\sigma_{\mathrm{m}}$ is the surface tension of the mixture, $\sigma_{i}$ is the surface tension of pure component, $A_{i}$ is the molar surface area of the $i$ th pure component, $\overline{A_{i}}$ is the partial molar surface area of component $i$ relative to mixture, $R$ is the gas constant, $T$ is the temperature, $\varphi$ is the fugacity coefficient, $y$ is the mole fraction, the subscript $\mathrm{S}$ and $\mathrm{B}$ indicate surface phase and bulk phase, respectively.

For the surface tension $\sigma_{i}$ of the pure agent, the following correlation in Eq. (2) provided by Nicola et al. $[16,17]$ is adopted with a high precision.

$$
\sigma_{i}=0.658 p_{\mathrm{c}}^{0.618} T_{\mathrm{c}}^{0.34}(1+\omega)^{0.770}\left(1-T / T_{\mathrm{c}}\right)^{1.262}
$$

where $p_{\mathrm{c}}$ is the critical pressure, $T_{\mathrm{c}}$ is the critical temperature, $\omega$ is the acentric factor, $T$ is the thermodynamic temperature.

In order to use Eq. (1) to calculate the surface tension of the mixture, the following two assumptions are proposed [32].

(1) The partial mole surface area of component $i$ is assumed to be equal to the mole surface area of the pure component $i$, i.e., $\overline{A_{i}}=A_{i}$. Moreover, the surface phase is considered as monomolecular layer and molecule of each component is regarded as spherical. Consequently, $\overline{A_{i}}$ and $A_{i}$ can be calculated by Eq. (3):

$$
\bar{A}_{i}=A_{i}=\pi \cdot\left(\frac{3}{4 \pi}\right)^{2 / 3} N_{\mathrm{A}}^{1 / 3} v_{i \mathrm{~B}}^{2 / 3}=1.21 N_{\mathrm{A}}^{1 / 3} v_{i \mathrm{~B}}^{2 / 3}
$$

where $N_{\mathrm{A}}$ is Avogadro constant, $=6.02 \times 10^{23} \mathrm{~mol}^{-1}, v_{i \mathrm{~B}}$ is the molar volume of liquid phase for pure component $i$.

(2) Assuming that the correlation of the fugacity coefficient and component for the surface phase and bulk phase can be described by equation of state and mixing rule. Because the component $y_{i \mathrm{~B}}$ and fugacity coefficient $\varphi_{i \mathrm{~B}}$ in the bulk phase follow vapor-liquid equilibrium, they can be calculated by using appropriate equation of state and mixing rule. Thus, they are regarded as the known constant.

In the current study, the PR equation of state was used, which can be expressed as the following:

$$
p=\frac{R T}{v-b}-\frac{a}{v(v+b)+b(v-b)}
$$


where $a$ and $b$ are the function of temperature. According to the critical parameters and reduced parameters, both variables can be obtained from the following expressions:

$$
\begin{gathered}
a=a_{\mathrm{c}} \alpha\left(T_{\mathrm{r}}\right)=\frac{0.45724 R^{2} T_{\mathrm{c}}^{2} \alpha\left(T_{\mathrm{r}}\right)}{p_{\mathrm{c}}} \\
b=\frac{0.07780 R T_{\mathrm{c}}}{p_{\mathrm{c}}} \\
\alpha\left(T_{\mathrm{r}}\right)=\left[1+\kappa\left(1-T_{\mathrm{r}}^{0.5}\right)\right]^{2}
\end{gathered}
$$

where $T_{\mathrm{r}}$ is the reduced temperature, $\kappa$ is the constant characteristic of each component.

In general, Eq. (4) is transformed into cubic equation in one variable corresponding to compressibility factor $Z$, which can be expressed as [33]:

$$
Z^{3}-(1-B) Z^{2}+\left(A-3 B^{2}-2 B\right) Z-\left(A B-B^{2}-B^{3}\right)=0
$$

where

$$
\begin{gathered}
A=\frac{a p}{R^{2} T^{2}} \\
B=\frac{b p}{R T} \\
Z=\frac{p v}{R T}
\end{gathered}
$$

In the current work, the one variable mixing rule of van der Waals is used to define the mixture parameters in Eqs. (9) - (11):

$$
\begin{gathered}
a_{\mathrm{m}}=\sum_{i} \sum_{j} x_{i} x_{j} a_{i j} \\
b_{\mathrm{m}}=\sum_{i} x_{i} b_{i} \\
a_{i j}=\left(a_{i} a_{j}\right)^{0.5}\left(1-k_{i j}\right)
\end{gathered}
$$

where $k_{i j}$ is the binary interaction parameter. For nitrogen and different extinguishing agents, the calculation method of the binary interaction parameters was described in Ref. [34].

Consequently, the equations predicting the surface tension of mixture are as follows: 


$$
\left\{\begin{array}{l}
\sigma_{\mathrm{m}}=\sigma_{i}+\frac{R T}{A_{i}} \ln \frac{\varphi_{i \mathrm{~S}} y_{i \mathrm{~S}}}{\varphi_{i \mathrm{~B}} y_{i \mathrm{~B}}} \\
\sum_{i=1}^{2} y_{i \mathrm{~S}}=1 \\
\sigma_{i}=0.658 p_{\mathrm{c}}^{0.618} T_{\mathrm{c}}^{0.34}(1+\omega)^{0.770}\left(1-T / T_{\mathrm{c}}\right)^{1.262}
\end{array}\right.
$$

In Eq. (16), the unknown variables are $y_{1 \mathrm{~s}}, y_{2 \mathrm{~S}}$ and $\sigma_{\mathrm{m}}$, respectively. Therefore, these equations group is close and has unique solution, which can be obtained by using Newton iterative method.

\section{Fluid release model}

This paper mainly analyzes the critical condition of dissolved nitrogen evolution based on the discharge model proposed by Yang et al. [9], and discusses the effect of different filling pressures on the critical pressure of nitrogen evolution, to predict the release process of nitrogenextinguishant.

It is assumed that the liquid fire extinguishing agent is clean other than the dissolved nitrogen. The release of the agent is a rapidly depressurized process. Meanwhile, the liquid phase can be considered as experiencing an isothermal release process. The evolution of dissolved nitrogen is schematically illustrated in Fig. 1, where the size of the gas bubble is exaggerated.

Initial state

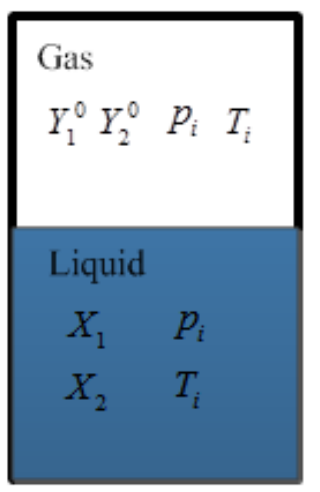

Liquid release

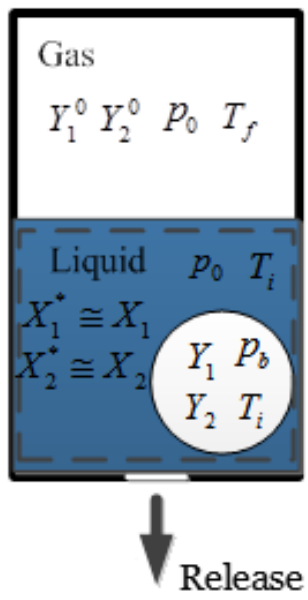

Partial enlarged view

Gas isentropic expansion

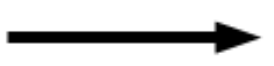

Liquid isothermal release

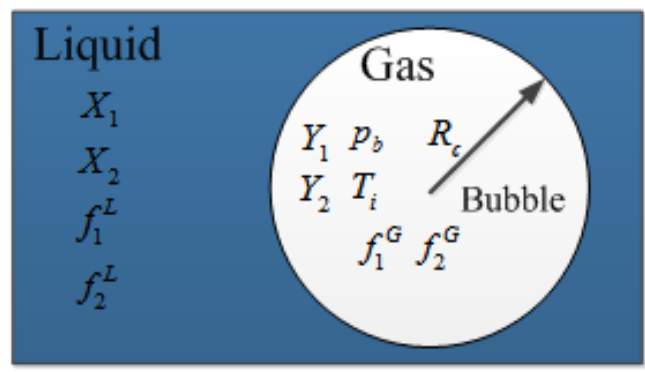


When the critical bubbles appear, the unstable thermodynamic equilibrium reaches between

the bubbles and surrounding superheated liquid. According to the theory of gas-liquid equilibrium, the fugacity is equal for nitrogen (denoted by ' 1 ' in Fig. 1) and fire extinguish agent (denoted by '2' in Fig. 1), as shown by the formula below.

$$
\begin{array}{r}
f_{1}^{L}\left(p_{0}, T_{i}, X_{1}\right)=f_{1}^{G}\left(p_{\mathrm{b}}, T_{i}, Y_{1}\right) \\
f_{2}^{L}\left(p_{0}, T_{i}, X_{2}\right)=f_{2}^{G}\left(p_{\mathrm{b}}, T_{i}, Y_{2}\right)
\end{array}
$$

where $X_{1}$ and $X_{2}$ are the mole fractions of nitrogen and extinguishing agent in liquid phase, respectively; $Y_{1}$ and $Y_{2}$ are the mole fractions of nitrogen and agent vapor in vapor phase, respectively; $f_{1}^{G}$ and $f_{2}^{G}$ are the fugacity for nitrogen and agent vapor in vapor phase, respectively; $f_{1}^{L}$ and $f_{2}^{L}$ are the fugacity for nitrogen and agent in liquid phase, respectively; $P_{0}$ is the liquid pressure outside bubble; $P_{\mathrm{b}}$ is the pressure inside bubble.

The pressure at the interface of bubble and liquid agent should meet the Yang-Laplace equation:

$$
p_{\mathrm{b}}-p_{0}=\frac{2 \sigma_{\mathrm{m}}}{R_{\mathrm{c}}}
$$

where $R_{\mathrm{c}}$ is the critical radius of bubble.

It can be seen from Eq. (8) to (10) that there are four unknown variables in total, namely $P_{\mathrm{b}}$, $P_{0}, Y_{1}$ and $R_{\mathrm{c}}$. One more equation needs to be supplemented to achieve a solution. Referring to the theory of superheat limit kinetics of binary mixture proposed by Holden and Katz [35], Yang et al. [9] added an equation regarding the nucleation rates $J$, in the form as below:

$$
J=\frac{N_{A}}{v^{L}}\left(\frac{Y_{1}}{\sqrt{M_{1}}}+\frac{Y_{2}}{\sqrt{M_{2}}}\right)\left(\frac{2 \sigma}{\pi}\right)^{0.5} \exp \left(\frac{-4 \pi \sigma R_{\mathrm{c}}^{2}}{3 k T_{i}}\right)
$$

where $M_{1}$ and $M_{2}$ are the molecular masses of the nitrogen and agent, respectively.

The results from Yang et al. [9] show that the calculated nitrogen escaping pressure is remarkably lower than the experimental data, although their model shown as Eq. (17) - (20) can accurately determine whether nitrogen gas has escaped during the release of fire extinguishing agent. Therefore, it can only be used to describe the changing trend of nitrogen escaping pressure. In view of this, Eq. (20) is not used as a supplementary equation in the current work, but the 
critical radius of escaping nitrogen bubble $\left(R_{\mathrm{c}}\right)$ under different initial conditions is directly assumed to be constant.

In order to solve the unknown variables in the equation, the scenario of the critical radius of nitrogen bubble approaching infinity is first analyzed.

As the critical radius tends to infinity, the thermodynamic equilibrium for the fluids on both sides of the bubble is shown in Fig. 2. Where, $P_{\mathrm{e}}$ and $T_{i}$ are the bubble-point pressure and temperature, respectively, when the gas-liquid equilibrium is reached.

Gas

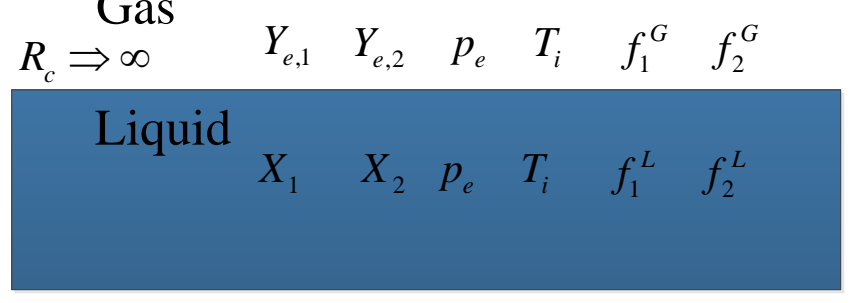

Fig. 2 The thermodynamic equilibrium at gas-liquid interface for infinite bubble radius

From the theory of gas-liquid phase equilibrium $[36,37]$, the fugacity of nitrogen and agent are equal at both sides of the bubble.

$$
\begin{aligned}
{\left[f_{2}^{L}\left(p_{e}, T_{i}, X_{2}\right)\right]_{R_{\mathrm{C}} \rightarrow \infty} } & =\left[f_{2}^{G}\left(p_{e}, T_{i}, Y_{e, 2}\right)\right]_{R_{C} \rightarrow \infty} \\
{\left[f_{1}^{L}\left(p_{e}, T_{i}, X_{1}\right)\right]_{R_{C} \rightarrow \infty} } & =\left[f_{1}^{G}\left(p_{e}, T_{i}, Y_{e, 1}\right)\right]_{R_{C} \rightarrow \infty}
\end{aligned}
$$

According to the thermodynamic theory, the fugacity for nitrogen and agent can be defined by Eq. (22).

$$
\left[\frac{\partial \ln f_{i}}{\partial p}\right]_{T_{i}}=\frac{\bar{v}_{i}}{R T_{i}}
$$

Integrate the equation above:

$$
R T_{i} \int_{\left[f_{2}^{L}\right]_{R_{c} \rightarrow \infty}}^{f^{L}} d \ln f_{2}^{L}=\int_{p_{e}}^{p_{0}} \bar{v}_{2}^{L} d p
$$

If assuming the partial molar volume of the liquid agent is only a function of temperature, and slightly affected by pressure and composition, then the above integral turns into:

$$
f_{2}^{L}=\left[f_{2}^{L}\right]_{R_{c} \rightarrow \infty} \exp \left[\frac{\bar{v}_{2}^{L}\left(p_{0}-p_{e}\right)}{R T_{i}}\right]
$$

Substituting Eq. (18) and Eq. (21) into the Eq. (25) can obtain: 


$$
f_{2}^{G}=\left[f_{2}^{G}\right]_{R_{\mathrm{c}} \rightarrow \infty} \exp \left[\frac{\bar{v}_{2}^{L}\left(p_{0}-p_{e}\right)}{R T_{i}}\right]
$$

296

297

298

299

300

301

302

303

304

305

306

307

308

309

310 Using the implicit function derivation rule, $\left(\frac{\partial Z}{\partial X_{2}}\right)_{T, p}$ can be calculated as the process below:

311

$$
\left(\frac{\partial Z}{\partial X_{2}}\right)_{T, p}=\frac{\left[-Z^{2}+2 Z(1+3 B)+A-2 B-6 B^{2}\right]\left(\frac{\partial B}{\partial X_{2}}\right)_{T, p}}{3 Z^{2}-2(1-B) Z+\left(A-3 B^{2}-B^{3}\right)}+\frac{(B-Z)\left(\frac{\partial A}{\partial X_{2}}\right)_{T, p}}{3 Z^{2}-2(1-B) Z+\left(A-3 B^{2}-B^{3}\right)}
$$

$$
\begin{gathered}
\bar{v}_{2}^{L}=\frac{R T}{p}\left[Z+X_{1}\left(\frac{\partial Z}{\partial X_{2}}\right)_{T, P}\right] \\
\bar{v}_{1}^{L}=\frac{R T}{p}\left[Z-X_{2}\left(\frac{\partial Z}{\partial X_{2}}\right)_{T, P}\right]
\end{gathered}
$$

313 where,

314

$$
\left(\frac{\partial A}{\partial X_{2}}\right)_{T, p}=\frac{p}{R^{2} T^{2}}\left[2 a_{22} X_{2}-2 a_{11} X_{1}+2\left(1-2 X_{2}\right)\left(1-k_{12}\right) \sqrt{a_{11} a_{22}}\right], \quad\left(\frac{\partial B}{\partial X_{2}}\right)_{T, p}=\frac{p}{R T}\left[b_{22}-b_{11}\right]
$$


When the bubble radius approaching infinity $\left(R_{\mathrm{c}} \rightarrow \infty\right)$, and the liquid temperature $\left(T_{i}\right)$ and the mole fraction $\left(X_{2}\right)$ of liquid phase agent is given, the pressure and the mole fraction of the agent vapor inside bubble can be obtained via a simple gas-liquid equilibrium calculation using the PR equation and the van der Waals mixing rule. Combining Eq. (28) and (29), the molar fractions for nitrogen $\left(Y_{1}\right)$ and agent vapor $\left(Y_{2}\right)$ in the nucleating bubble can be obtained.

Taking the nitrogen evolution during the release of Halon1301 as an example, this study assumes that the critical radii are different constants in this process. Therefore, to evaluate the accuracy of the model proposed by the authors, the critical escaping pressures calculated by different critical radii will be compared with the experimental data.

When the evolution of the nitrogen happening and the values of $T_{i} 、 X_{1} 、 X_{2}$ and $R_{\mathrm{c}}$ are given, the process of calculating the critical pressure within the nucleation bubble $\left(p_{\mathrm{b}}\right)$, the pressure of the liquid phase $\left(p_{0}\right)$, and the molar ratio of nitrogen in bubble $\left(Y_{1}\right)$ are as follow:

(1) According to the given values $T_{i} 、 X_{1}$ and $X_{2}$, the values for $p_{\mathrm{e}}, Y_{e, 1}$ and $Y_{e, 2}$ can be acquired through the bubble point pressure calculation (bubble point pressure calculation refer to Ref. [34]).

(2) Calculate the compression factor $Z\left(p_{e}, T_{i}, X_{2}\right)$ corresponding to $p_{e}, T_{i}$, and $X_{2}$.

(3) Calculate the partial molar volume $\bar{v}_{1}^{L}\left(p_{e}, T_{i}, X_{1}\right)$ and $\bar{v}_{2}^{L}\left(p_{e}, T_{i}, X_{2}\right)$, of nitrogen and agent, respectively.

(4) Based on $Z\left(p_{e}, T_{i}, X_{2}\right), p_{e}$ and $T_{i}$, calculate the molar volume $v^{L}\left(p_{e}, T_{i}, X_{2}\right)$ of liquid mixture.

(5) Assume $p_{0}=1.0 \mathrm{MPa}$.

(6) Use Eq. (28) and (29) to calculate $p_{0}, Y_{1}$, and $Y_{2}$.

(7) Calculate the new $p_{0}$ through Eq. (19).

(8) Compare the calculated $p_{0}$, stop the calculation as meet $\left|p_{0}^{\text {new }}-p_{0}^{\text {old }}\right|<0.001$, otherwise go to step 6 for recalculation.

Since nitrogen is a type of insoluble gas in all fire extinguishing agents, the gas mixture and liquid fire extinguishing agent in the fire extinguisher still show obvious stratification even under high filling pressure. It is recognized that the release of the liquid fire extinguishing agent can only last tens of milliseconds after the valve is opened. Therefore, it could be assumed that the energy exchange and mass exchange between the gas mixture and the liquid are strictly 
restricted. Moreover, the release of the liquid fire extinguishing agent can be considered as the isothermal decompression process, while the gas mixture undergoes the adiabatic reversible process of actual gas.

Yang et al. [8] did not distinguish the type of the fire extinguishing agent and the filling pressure strictly, and the adiabatic index was taken as 1.4 when analyzing the fluid release process. However, the mole ratio of Halon1301 vapor in the gas mixture in the fire extinguisher is 0.49 when the typical filling pressure is $4.2 \mathrm{MPa}$ [38]. As a result, it is necessary to consider the influence of the nitrogen and fire extinguishing agent vapor simultaneously when developing the model of the fluid release process in fire extinguisher.

According to the differential relation of the thermodynamics, the calculation formula of the volume adiabatic index $k_{v}$ and the temperature adiabatic index $k_{T}$ is as follows:

$$
k_{v}=\frac{Z}{Z_{p}-R Z_{T}^{2} / c_{p}}
$$

where, $c_{\mathrm{p}}$ is the specific heat capacity of the actual gas at constant pressure, $\mathrm{J} /(\mathrm{mol} \cdot \mathrm{K}) ; Z_{p}$ and $Z_{T}$ are derivative compression factors, and the definition formulas are as follows:

$$
Z_{p}=Z-p\left(\frac{\partial Z}{\partial p}\right)_{T}
$$

$$
Z_{T}=Z+T\left(\frac{\partial Z}{\partial T}\right)_{p}
$$

Since the gas mixture is only composed of nitrogen and extinguishing agent steam, the PR equation of state and van der Waals mixing rule are selected to calculate the above derivative compression factor of gas mixture.

For gas mixtures, the PR equation is expressed in the form of cubic equation of compression factor $Z$ as follows:

$$
Z^{3}-\left(1-B_{\mathrm{m}}\right) Z^{2}+\left(A_{\mathrm{m}}-3 B_{\mathrm{m}}^{2}-2 B_{\mathrm{m}}\right) Z-\left(A_{\mathrm{m}} B_{\mathrm{m}}-B_{\mathrm{m}}^{2}-B_{\mathrm{m}}^{3}\right)=0
$$

where, $A_{\mathrm{m}}=a_{\mathrm{m}} p / R^{2} T^{2} ; B_{\mathrm{m}}=b_{\mathrm{m}} p / R T ; Z=p v_{\mathrm{m}} / R T$.

For the cubic equation of the compression factor, the partial derivatives of pressure and temperature are respectively calculated by implicit differentiation, and then substituted into the 
equation of the derivative compression factor, finally the calculation formula of the gas mixture's derivative compression factor can be obtained as follows:

$$
\begin{gathered}
\left.\frac{\partial A_{\mathrm{m}}}{\partial T}\right|_{P}=-\frac{p}{R^{2} T^{3}}\left[a_{1} E_{1} y_{1}^{2}+y_{1} y_{2}\left(1-k_{12}\right) \sqrt{a_{1} a_{2}}\left(E_{1}+E_{2}\right)+a_{2} E_{2} y_{2}^{2}+2 a_{\mathrm{m}}\right] \\
\left.\frac{\partial B_{\mathrm{m}}}{\partial T}\right|_{P}=-\frac{B_{\mathrm{m}}}{T}
\end{gathered}
$$$$
Z_{p}=Z-p\left(\frac{\partial Z}{\partial p}\right)_{T}=Z-\frac{2 A_{\mathrm{m}} B_{\mathrm{m}}-2 B_{\mathrm{m}}^{2}-3 B_{\mathrm{m}}^{3}-Z^{2} B_{\mathrm{m}}-Z\left(A-6 B_{\mathrm{m}}^{2}-2 B_{\mathrm{m}}\right)}{3 Z^{2}-2\left(1-B_{\mathrm{m}}\right) Z+\left(A-3 B_{\mathrm{m}}^{2}-B_{\mathrm{m}}^{3}\right)}
$$$$
Z_{T}=Z+T\left(\frac{\partial Z}{\partial T}\right)_{p}
$$$$
=Z+\frac{B_{\mathrm{m}} Z^{2}+\left[-6 B^{2}-2 B+p / R^{2} T^{2}\left(\frac{\partial A_{\mathrm{m}}}{\partial T}\right)_{p}\right] Z-B p / R^{2} T^{2}\left(\frac{\partial A_{\mathrm{m}}}{\partial T}\right)_{p}}{3 Z^{2}-2\left(1-B_{\mathrm{m}}\right) Z+\left(A-3 B_{\mathrm{m}}^{2}-B_{\mathrm{m}}^{3}\right)}
$$$$
-\frac{A_{\mathrm{m}} B_{\mathrm{m}}+2 B_{\mathrm{m}}^{2}+3 B_{\mathrm{m}}^{3}}{3 Z^{2}-2\left(1-B_{\mathrm{m}}\right) Z+\left(A-3 B_{\mathrm{m}}^{2}-B_{\mathrm{m}}^{3}\right)}
$$

where, $E_{1}=k_{1} \sqrt{T_{1, \mathrm{r}} / \alpha_{1}} ; \quad E_{2}=k_{2} \sqrt{T_{2, \mathrm{r}} / \alpha_{2}}$.

In addition, the specific heat capacity $c_{p, \mathrm{~m}}$ of the mixture of nitrogen and extinguishing agent steam under pressure can be calculated by the following formula:

$$
c_{p, \mathrm{~m}}=\sum_{i} c_{p, i} y_{i}
$$

where, $y_{i}$ is the mole fraction of each component; $c_{p, i}$ is the specific heat capacity of each component at constant pressure.

Based on the above method of critical pressure of nitrogen and adiabatic index of gas mixture, the release model of gas mixture of nitrogen and extinguishing agent steam is finally obtained as follows:

$$
\frac{d p}{d t}+\frac{p k_{V}}{V_{\mathrm{b}}} C_{d} A \sqrt{\frac{2\left(p-p_{a}\right)}{\rho_{l, m}}}=0
$$

where, $V_{\mathrm{b}}$ is the volume of the fire extinguisher; $C_{d}$ is the liquid emission coefficient, and the NIST recommended value is 0.61 to 0.64 [8]; $A$ is the cross-sectional area of the small hole; $p_{a}$ is the atmospheric ambient pressure.

The total pressure in the fire extinguisher at each time step in the above formula can be calculated by the fourth-order Runge Kutta method [39]. Before the liquid phase at the bottom 
of the fire extinguisher is released completely, if the pressure in the fire extinguisher is less than the predicted value of critical pressure of nitrogen evolution, it can be determined that the nitrogen escapes, and the gas-liquid interface after nitrogen escapes needs to be redefined; otherwise, the nitrogen will not escape during the whole releasing process.

If nitrogen does not escape during the release of the extinguishing agent, the gas mixture will be filled with the fire extinguisher after the release. Therefore, the subsequent release process can be treated as an open system. In the current work, the calculation model mentioned in Ref. [8] can be used:

$$
\frac{p}{p_{\text {full }}}=\left[1-\frac{C_{A} A}{V_{\mathrm{b}}}\left(\frac{R T_{\text {full }} k_{V}^{3} K}{m}\right)^{0.5}\left(\frac{1-k_{V}}{2 k_{V}}\right) t\right]^{\frac{2 k_{V}}{1-k_{V}}}
$$

where, $K=\left[1 /\left(k_{V}+1\right)\right]^{\left(k_{V}+1\right) /\left(k_{V}-1\right)}, C_{A}$ is the gas emission coefficient, and the value is $0.61 ; m$ is the equivalent molecular mass of the gas mixture which can be calculated according to the molar components of nitrogen and fire extinguishing agent steam; $p_{\text {full }}$ and $T_{\text {full }}$ are the pressure and temperature respectively at the moment when the liquid is released and the gas mixture is filled with the fire extinguisher.

If nitrogen escapes during the release of the liquid extinguishing agent, the volume of the gas mixture and liquid after nitrogen escapes must be recalculated separately. In the current study, it is assumed that all the escaping bubbles stay in the liquid layer while the process of the subsequent bubble growth and rising are ignored. Therefore, the escape of the nitrogen makes the liquid layer expand upward and the gas phase space decrease correspondingly. If this process is regarded as isentropic change, the pressure formula of compressed gas phase space is as follows:

$$
p^{\prime}=p_{\text {bd }}\left(\frac{V_{\text {bd }}}{V_{\text {compress }}}\right)^{k_{V}}
$$

where, $p_{\mathrm{bd}}$ and $V_{\mathrm{bd}}$ are pressure and volume of the gas mixture in the fire extinguisher before nitrogen escaping respectively.

\section{Results and discussion}

\subsection{Surface tension of nitrogen-extinguishant mixture}

The dissolved nitrogen can change the surface tension of the mixture of fire extinguishing 
agent and nitrogen. According to the literature review, there is no experimental data regarding the surface tension of binary mixture of nitrogen and extinguishing agents. To verify the accuracy of Eq. (16), the surface tension of nitrogen-ethane mixture in Ref. [27] are cited for evaluation. The temperature range for the selected data is $253 \mathrm{~K}-283 \mathrm{~K}$, and the pressure range is $1.44 \mathrm{MPa}-3.92 \mathrm{MPa}$. The calculated results are compared to the experimental data in Ref. [27], as shown in Fig. 3.

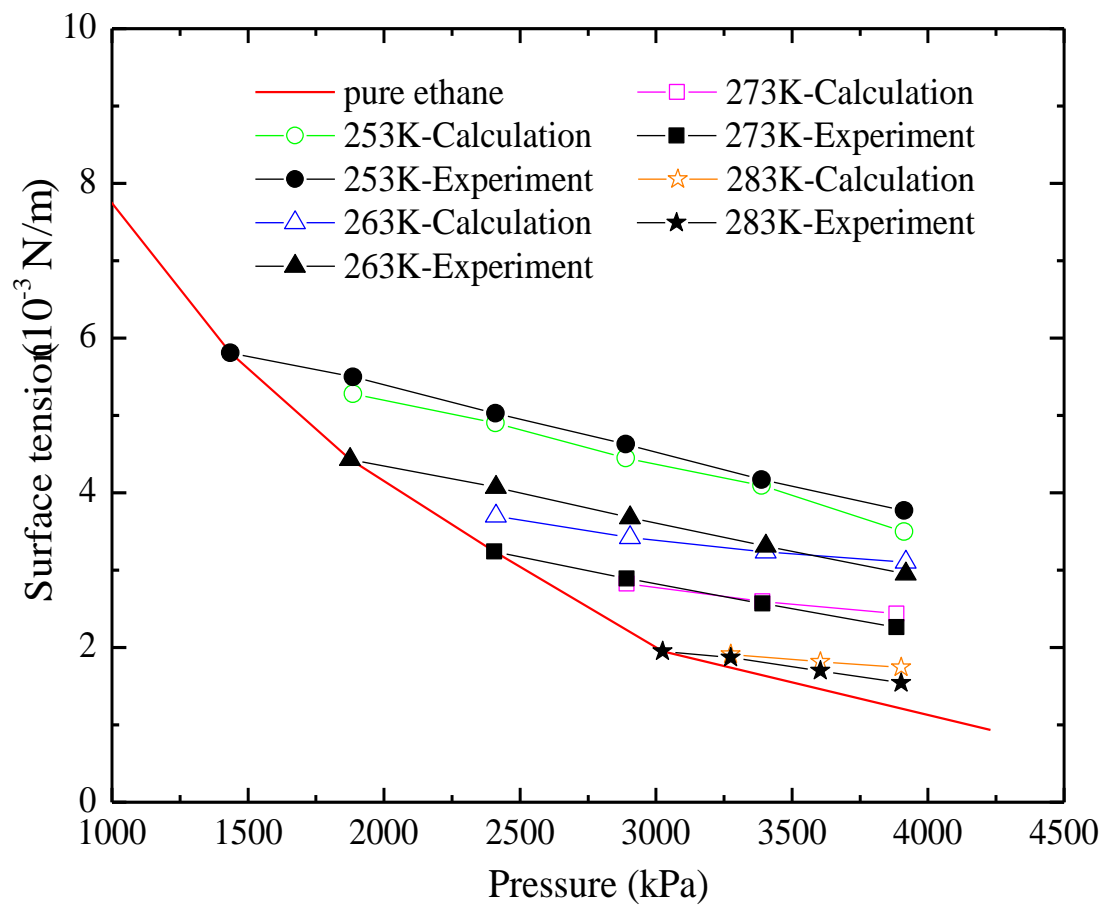

Fig. 3 Comparison between the calculated and experimental data for nitrogen-ethane mixture

Fig. 3 shows that the surface tension of nitrogen-ethane solution decreases with the temperature and pressure increasing. Compared to the surface tension of pure ethane, the surface tension of mixture decreases approximately linearly as the amount of dissolved nitrogen gradually increases. In the range of investigated temperature and pressure, the surface tension calculated by Eq. (16) is basically consistent with the experimental data, with an average relative deviation less than $2.8 \%$, which verifies that the model to predict surface tension of mixture is accurate and effective.

Taking Halon1301 as an example, the influence of different filling pressures on the surface tension of nitrogen- extinguishant mixture is analyzed. The given operating conditions are as follow: the volume of fire extinguisher is $2.35 \times 10^{-3} \mathrm{~m}^{3}$, the filling amount of Halon1301 is 1.89 $\mathrm{kg}$, the filling temperature is $293.15 \mathrm{~K}$, and the filling pressure is $2.5 \mathrm{MPa}$ and $4.2 \mathrm{MPa}$. 
The calculated results for the surface tension of nitrogen-Halon1301 solution under different filling pressures are shown in Fig. 4. As can be seen from Fig. 4, the surface tension of the mixture gradually decreases with the increase of filling pressure at the same temperature. Given that filling pressure is 4.2 $\mathrm{MPa}$, the surface tension for nitrogen-Halon 1301 solution is only $65 \%$ of that for pure Halon1301, which means that the absolute difference between the two cases is $1.5 \times 10^{-3} \mathrm{~N} / \mathrm{m}$. Therefore, the effect of dissolved nitrogen needs to be considered when calculating the escaping pressure of nitrogen during the release of the fire extinguishing agent.

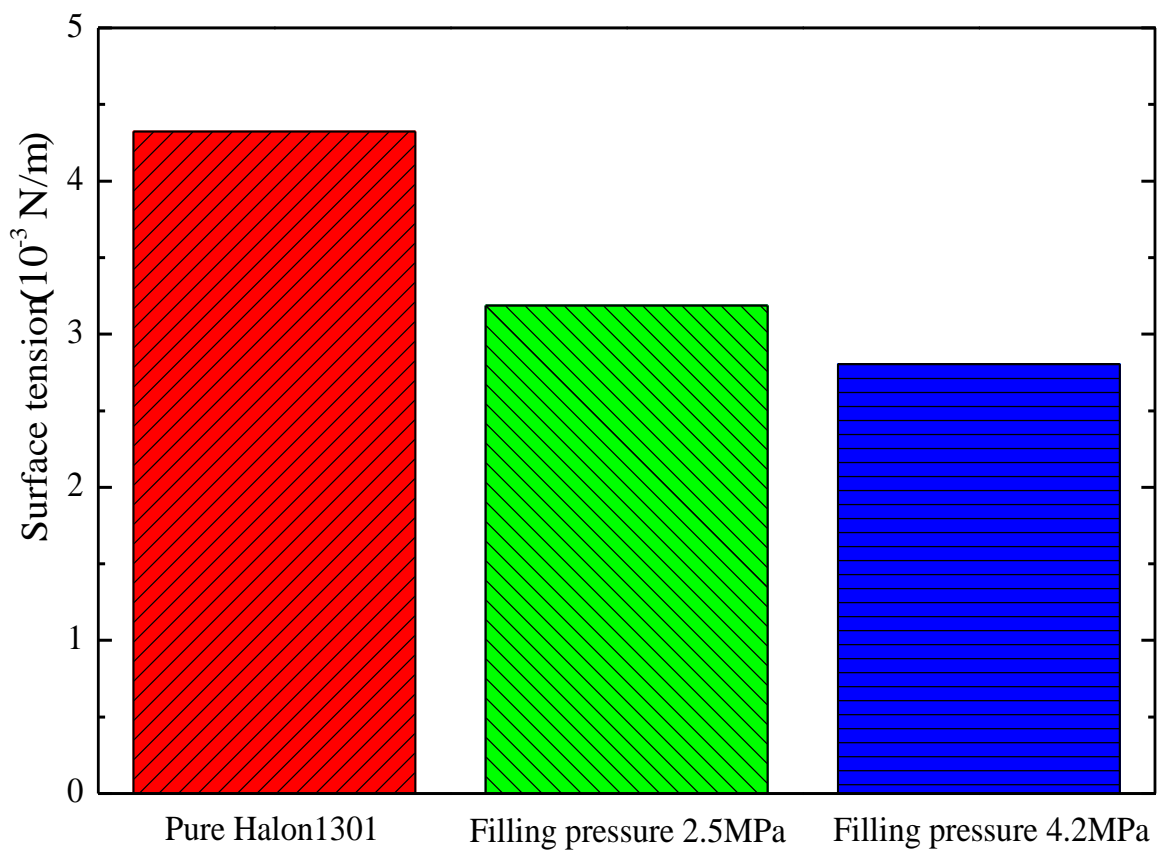

Fig. 4 The surface tension of nitrogen-Halon1301 solution under different operating conditions

\subsection{Critical pressure of nitrogen evolution}

Some extensive experiments on Halon1301 release were carried out by Elliot et al. [7] and the critical pressures when the evolution of the nitrogen happening were recorded. These provide an experimental evidence for comparing the accuracy of different nitrogen evolution prediction models. When calculating the critical pressure of nitrogen evolution, both Elliot et al. [7] and Yang et al. [9] directly used the equation which calculates the surface tension of pure substance, but ignored the influence of dissolved nitrogen on the surface tension of the agent. However, it has been analyzed in section 4.1 that the dissolved nitrogen has an obvious effect on the surface tension of the agent. Therefore, the equation to calculate surface tension of the nitrogenextinguishant mixture is employed in this study to calculate the escaping pressure of the nitrogen. When the critical radius is set as $6 \mathrm{~nm} \sim 9 \mathrm{~nm}$, the comparison between the predicted and the 
experimental value of the critical pressure of the nitrogen escaping is presented in Fig. 5. The surface tension of the mixture of Halon1301 and nitrogen is assumed as that of a pure substance, which was calculated by Eq. (2). It can be found from Fig. 5 that as the critical pressure of nitrogen escaping is small (less than $3.5 \mathrm{MPa}$ ), the predicted critical pressure is closer to the experimental value for the critical radius of $6 \mathrm{~nm}$. When the critical pressure increases, the value of the critical radius should be increased to obtain more accuracy results. In general, as the critical radius is set as $6 \mathrm{~nm}, 7 \mathrm{~nm}, 7.5 \mathrm{~nm}, 8 \mathrm{~nm}$ and $9 \mathrm{~nm}$, the mean relative deviations between predicted and experimental values for the critical escaping pressure are $8.9 \%, 5.8 \%, 6.2 \%, 7.2 \%$ and $10.0 \%$, respectively. The critical radius between $7 \mathrm{~nm}$ and $7.5 \mathrm{~nm}$ is considered as a reasonable value for all the experimental cases. The result is in a good agreement with the value of the critical pressure suggested by Elliot et al. [7].

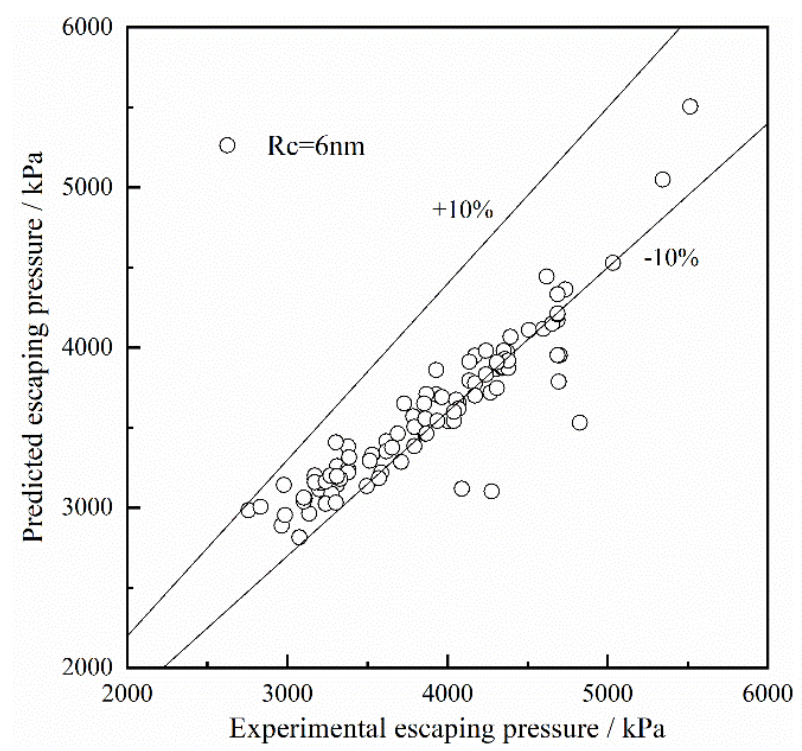

(a) Critical radius $6 \mathrm{~nm}$

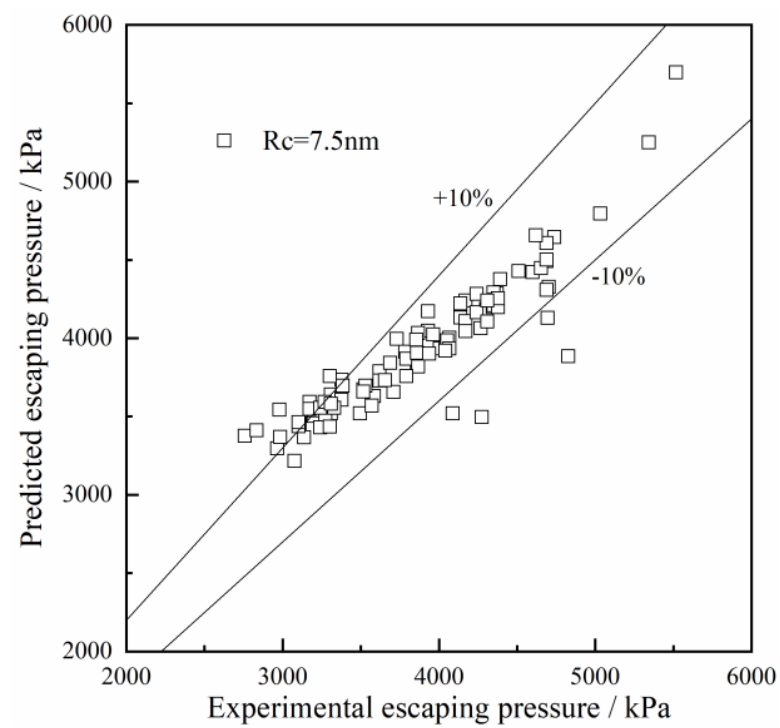

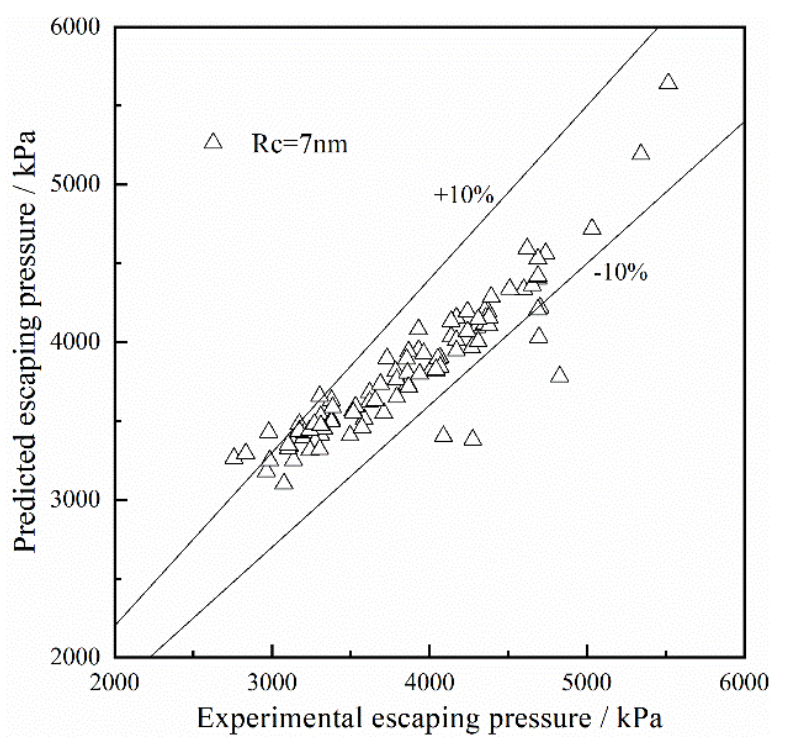

(b) Critical radius $7 \mathrm{~nm}$

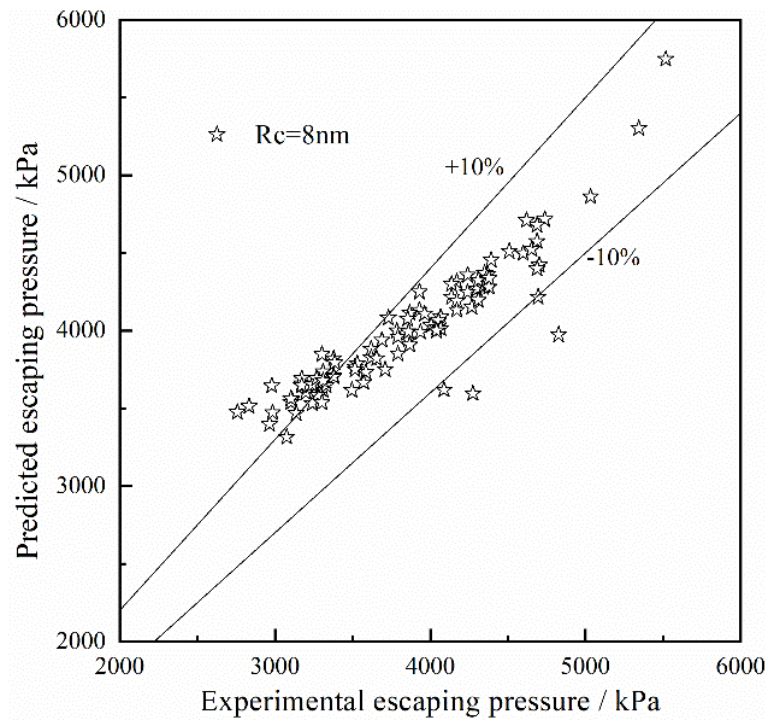




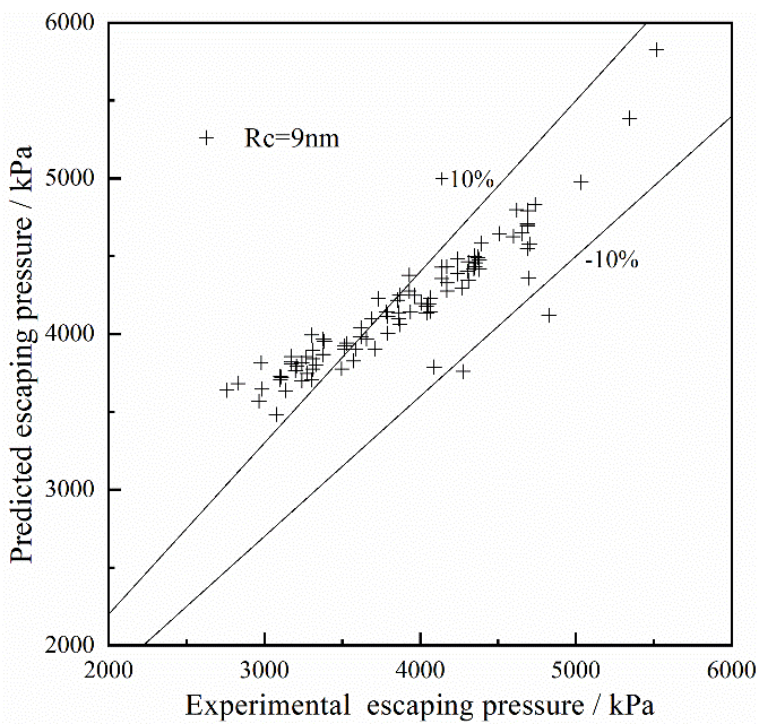

(e) Critical radius $9 \mathrm{~nm}$

Fig. 5 Comparison between the predicted and experimental value of critical escaping pressure using surface tension of a pure substance

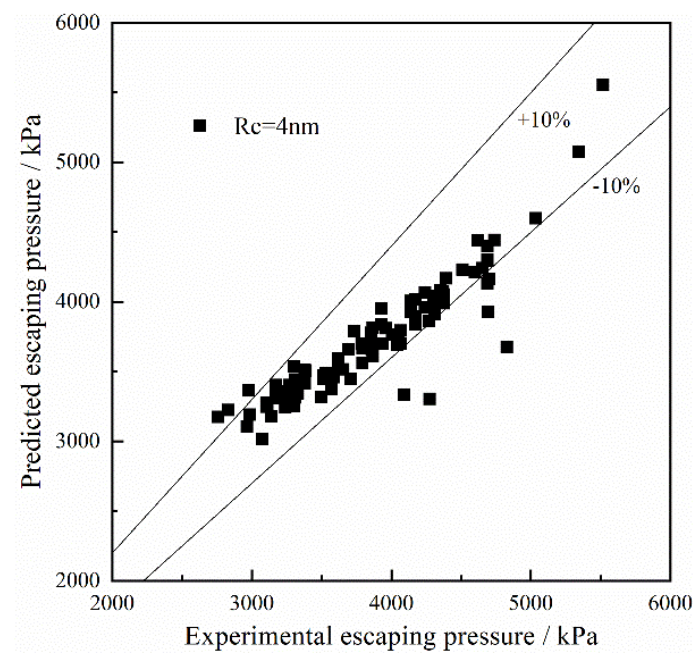

(a) Critical radius $4 \mathrm{~nm}$

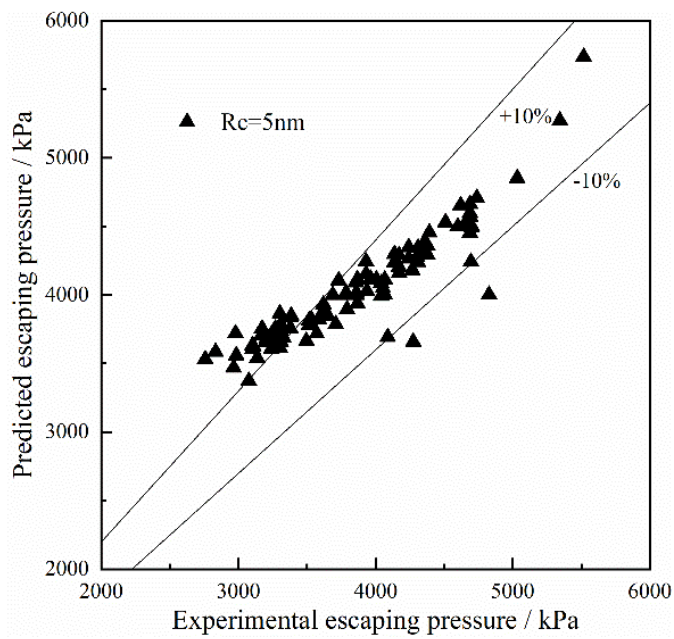

(c) Critical radius $5 \mathrm{~nm}$

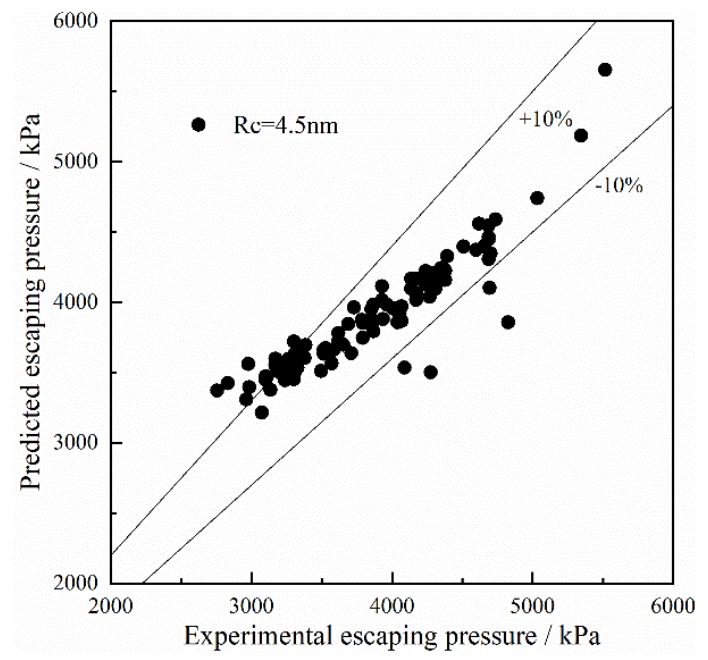

(b) Critical radius $4.5 \mathrm{~nm}$

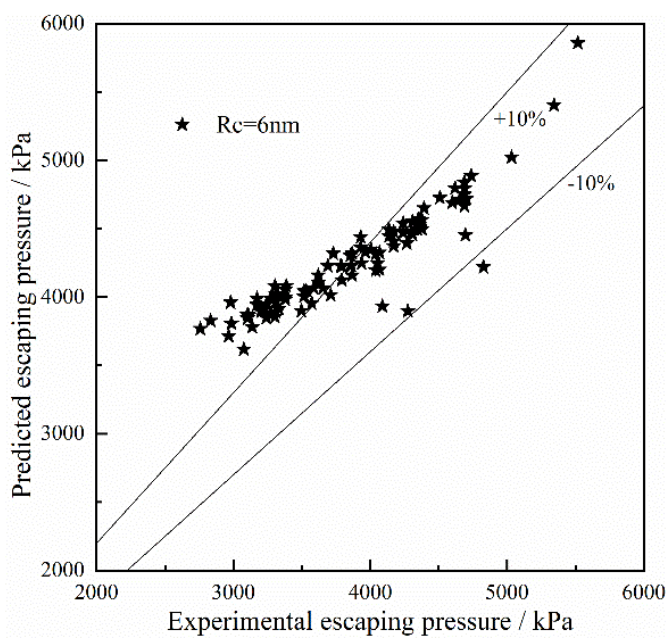

(d) Critical radius $6 \mathrm{~nm}$ 


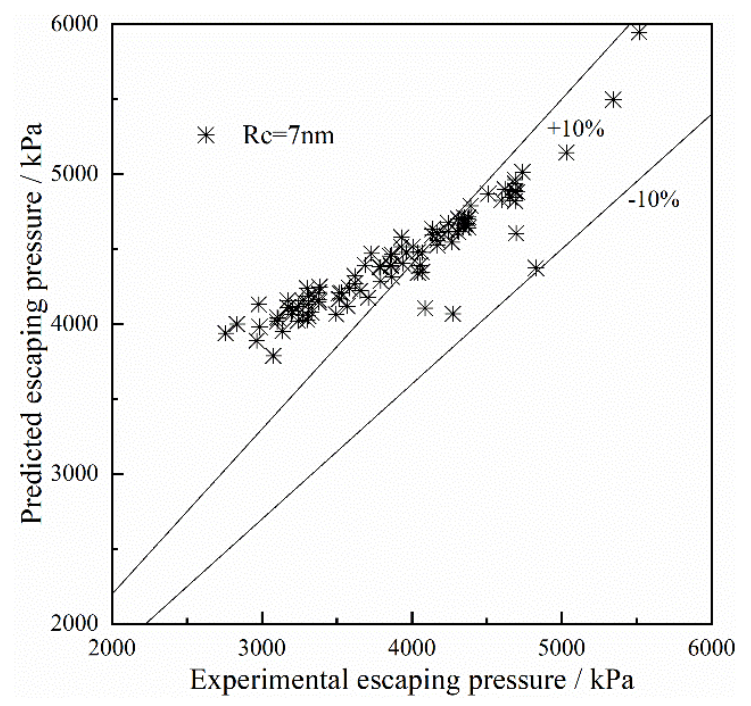

(e) Critical radius $7 \mathrm{~nm}$

Fig. 6 Comparison between the predicted and experimental value of critical escaping pressure using surface tension of mixture

When the critical radius is set as $4 \mathrm{~nm} \sim 7 \mathrm{~nm}$, the comparison between the predicted and the experimental value of the critical escaping pressure of the nitrogen is presented in Fig. 6. It should be noticed that if using the Eq. (1) to calculate surface tension the critical radius needs to be increased as the experimental critical escaping pressure of the nitrogen gradually raises. This can be explained by the Yang-Laplace equation, namely, the surface tension of nitrogenHalon1301 mixture is smaller than that of pure Halon1301 under the same conditions. Thus, the critical radius selected in Yang-Laplace equation also should be smaller. For all the nitrogen evolution experiments, the average relative deviations between predicted and experimental values for the critical escaping pressure are $6.4 \%, 6.5 \%, 7.9 \%, 12.4 \%$, and $16.2 \%$, for the critical radii of $4 \mathrm{~nm}, 4.5 \mathrm{~nm}, 5 \mathrm{~nm}, 6 \mathrm{~nm}$ and $7 \mathrm{~nm}$, respectively. For all the filling conditions, the critical radius of $4 \mathrm{~nm}$ is a more preferred.

\subsection{Nitrogen-extinguishant release process}

In this section, the fluid release model considering the surface tension of the mixture proposed in the current study is applied to predict the release process of Halon1301 and three kinds of halon alternatives at atmospheric pressure after filling with nitrogen to typical pressure. In order to evaluate the accuracy of the fluid release model, the pressure-time curves of the liquid extinguishant release and the gas mixture release phase are calculated and compared to the experimental data in Ref. [8].

The six known conditions of the validation cases are shown in Table 1 . In all cases, the 


\begin{tabular}{cccccc}
\hline Condition & $\begin{array}{c}\text { Type of } \\
\text { extinguishant }\end{array}$ & $\begin{array}{c}\text { Quality of } \\
\text { extinguishant/kg }\end{array}$ & $\begin{array}{c}\text { Filling } \\
\text { pressure/MPa }\end{array}$ & $\begin{array}{c}\text { Ambient } \\
\text { temperature/K }\end{array}$ & $\begin{array}{c}\text { Volume of } \\
\text { extinguisher } \\
/ 10^{-4} \mathrm{~m}^{3}\end{array}$ \\
\hline I & $\mathrm{CF}_{3} \mathrm{I}$ & 0.755 & 4.17 & 294.15 & 6.10 \\
II & FC218 & 0.450 & 4.04 & 295.15 & 6.10 \\
III & HFC125 & 0.438 & 4.03 & 294.15 & 6.10 \\
IV & Halon1301 & 0.591 & 4.10 & 295.15 & 6.10 \\
V & Halon1301 & 0.564 & 4.05 & 295.15 & 6.10 \\
VI & Halon1301 & 0.586 & 2.75 & 294.15 & 6.10 \\
\hline
\end{tabular}

equivalent diameters of the valve at the bottom of the fire extinguisher used are $24.5 \mathrm{~mm}$, and the critical radius of the nitrogen escape are taken as $4 \mathrm{~nm}$. For the mixtures of nitrogen- $\mathrm{CF}_{3} \mathrm{I}$, nitrogen-FC218, nitrogen-HFC125, and nitrogen-Halon1301 under corresponding operating condition, the calculated optimum binary interaction parameters are $0.02501,0.12328,0.17524$ and 0.04920 , respectively.

Table 1 The known conditions of the validation cases
511

The comparison between the predicted value and the experimental data of the release process of nitrogen-extinguishant under six different operating conditions is shown in Fig. 7, where the gauge pressure in the bottle has been converted into dimensionless pressure $p / p_{i}$, and Fig. 7 (a) to (f) correspond to the calculation results of conditions I to VI. Based on the fluid release model proposed in the current study, the critical pressures of the nitrogen escape under the six operating conditions are $0.94 \mathrm{MPa}, 2.58 \mathrm{MPa}, 2.41 \mathrm{MPa}, 2.53 \mathrm{MPa}, 2.49 \mathrm{MPa}$, and 1.23 $\mathrm{MPa}$, and the volume adiabatic indexes are $1.41,1.16,1.19,1.233,1.229$, and 1.127, respectively. Under conditions I and VI, the dissolved nitrogen does not escape, and the mixture release process clearly presents two stages: the liquid extinguishant release stage and the gas mixture release stage. However, the evolution phenomenon of the dissolved nitrogen occurs in the cases under conditions II to V in Fig. 7 due to the high filling pressure, accompanied by the transient increase of pressure in the fire extinguisher. The whole fluid release process presents four stages: 1) The superheated liquid release stage, accompanied by the decrease of pressure; 2) The nitrogen escaping stage, accompanied by the increase of pressure in the bottle; 3) The release stage of the two-phase fluid consisting of the escape bubble and liquid extinguishant; 4) The gas mixture release stage. 


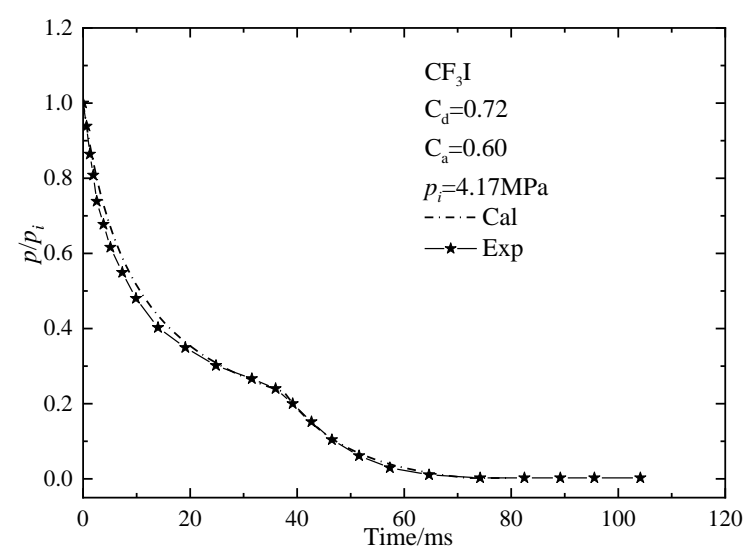

(a) Condition I

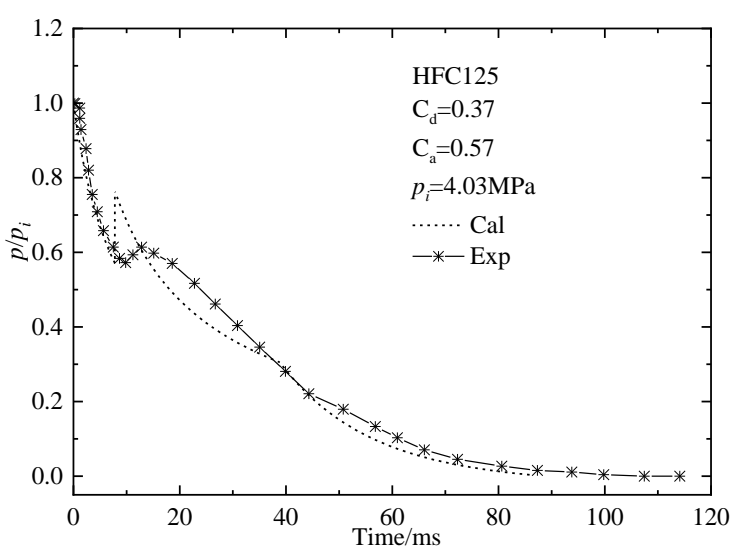

(c) Condition III

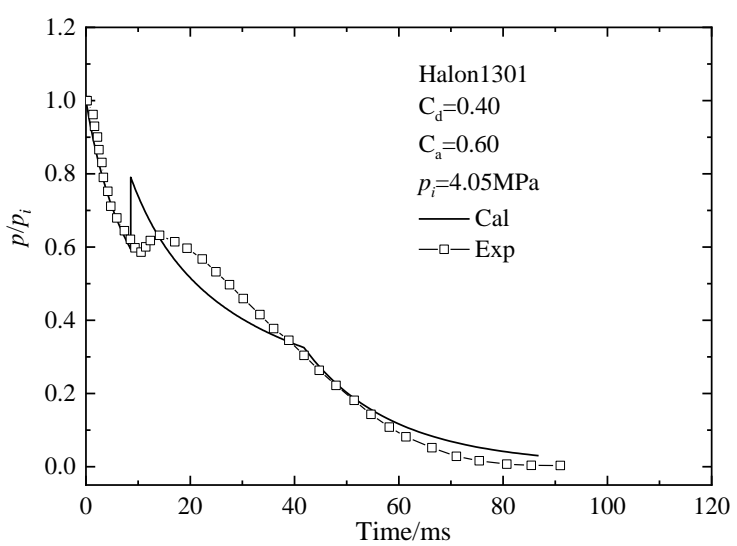

(e) Condition V

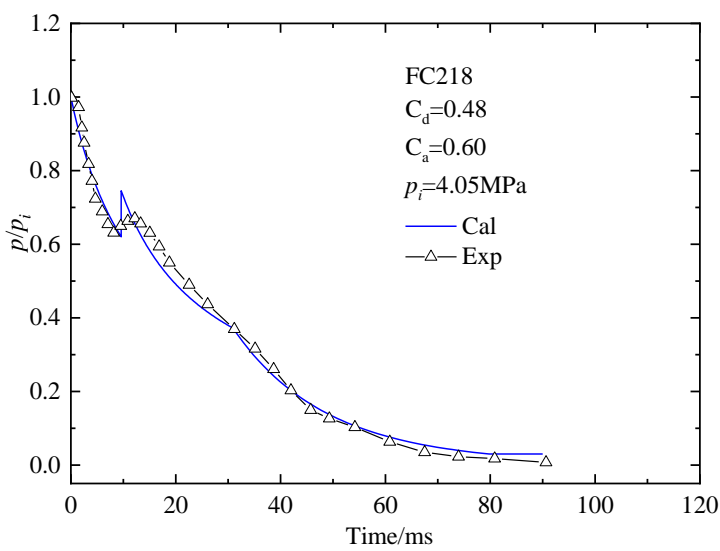

(b) Condition II

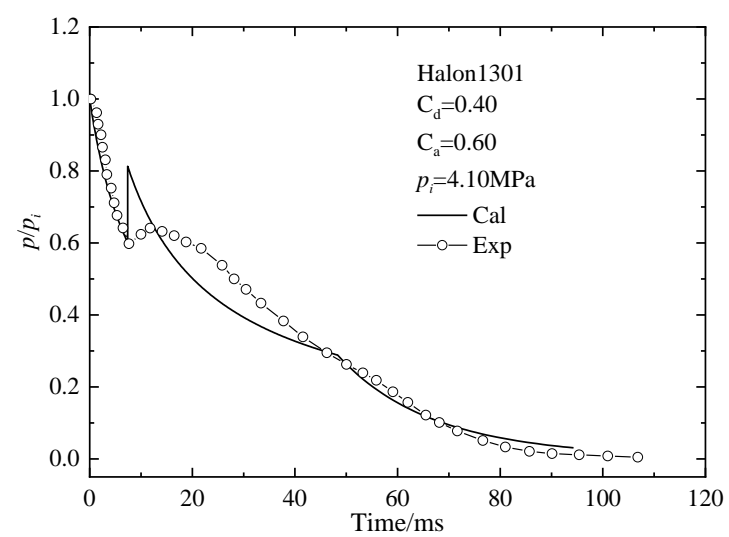

(d) Condition IV

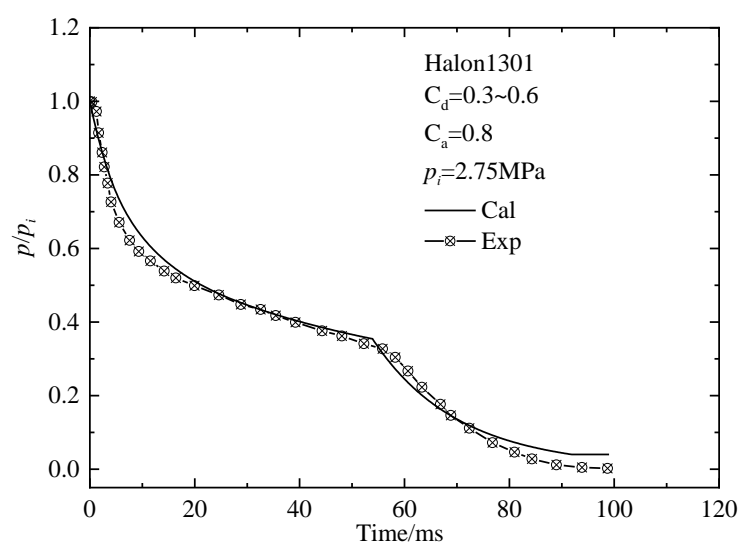

(f) Condition VI

Fig. 7 Comparison between predicted and experimental value of nitrogen-

\section{extinguishant release process}

According to the experimental data, the nitrogen escaping pressures under conditions II to $\mathrm{V}$ are about 2.66 MPa, 2.30 MPa, 2.51 MPa, and 2.43 MPa, and the corresponding average relative deviations between predicted value and experimental data are $3.0 \%, 4.8 \%, 0.8 \%$ and $2.5 \%$, respectively. Due to the neglect of the growth and rise process of the nitrogen bubble, the 
predicted pressures in the fire extinguisher during the release stage of two-phase flow are greater than the experimental data under conditions II to V, while the prediction results of other stages and conditions are in good agreement with the experimental data. Taking condition II as an example, the average relative deviation between the calculated and the experimental pressure in the liquid and two-phase fluid release stages is about 5.8\%, and that in the nitrogen-FC218 steam mixture release stage is about $4.7 \%$. In addition, the predicted and experimental gas mixtures are filled with the fire extinguisher at $32 \mathrm{~ms}$ and $35 \mathrm{~ms}$ respectively, with a difference of about $3 \mathrm{~ms}$.

Moreover, it is believed that the release model can be used to predict the other nitrogenextinguishant mixtures. In addition, it would be better that the verification is performed if the corresponding experimental data can be provided.

Therefore, it can be considered that the proposed release model can accurately predict the release process of multiple binary mixtures of nitrogen and fire extinguishing agent and calculate the change of pressure in the fire extinguisher with time.

\section{Conclusions}

According to PR equation of state and van der Waals mixing rule, this article calculates the surface tension of the fire extinguishing agent dissolved nitrogen based on the thermodynamic model. The results show that the surface tension of the liquid agent decreased obviously after it dissolved with nitrogen. Consequently, a prediction model of the critical escaping pressure of dissolved nitrogen during the release of fire extinguishing agent is developed based on the homogeneous nucleation theory. The critical radius value of nitrogen evolution is discussed. Comparing to critical pressure of nitrogen evolution reported in a large amount of Halon 1301 release experiments from literature, the results indicate that the average relative deviation between the predicted and experimental critical escaping pressure is approximate $6.4 \%$ when the critical radius of nitrogen evolution is $4 \mathrm{~nm}$. The prediction model can not only accurately determine whether the dissolved nitrogen evolution occur, but also calculate the critical escaping pressure of dissolved nitrogen more accurately. Moreover, an improved fluid release model is developed to predict the release process of various nitrogen-extinguishant binary systems, such as nitrogen- $\mathrm{CF}_{3} \mathrm{I}$, nitrogen-FC218, nitrogen-HFC125, and nitrogen-Halon1301. In comparison with the previous experimental data, the pressure-time curves in the liquid and the gas mixture release stage can be described well by the fluid release model. 


\section{References}

[1] Takahashi F, Katta VR, Linteris GT, Babushok VI. A computational study of extinguishment and enhancement of propane cup-burner flames by halon and alternative agents. Fire Saf J. 2017; 91: 688-694.

[2] Zhang T, Liu H, Han Z, Wang Y, Guo Z, Wang C. Experimental study on the synergistic effect of fire extinguishing by water and potassium salts. J Therm Anal Calorim. 2019; 138: $857-867$.

[3] Gann RG. Guidance for advanced fire suppression in aircraft. Fire Technol. 2008; 44(3): 263-282.

[4] Hodgs SE, McCormick SJ. Fire extinguishing agents for protection of occupied spaces in military ground vehicles. Fire Technol. 2013; 49(2): 379-394.

[5] Grosshandler WL, Gann RG, Pitts WM. Evaluation of alternative in-flight fire suppressants for full-scale testing in simulated aircraft engine nacelles and dry bays. NIST SP-861, Washington DC; 1994.

[6] Saso Y, Saito N, Liao C, Ogawa Y. Extinction of counterfiow diffusion flames with halon replacements. Fire Saf J. 1996; 26(4): 303-326.

[7] Elliott DG, Garrison PW, Klein GA, Moran KM, Zydowicz M P. Flow of nitrogen pressurized halon 1301 in fire extinguishing Systems. JPL Publication 84-62, Jet Propulsion Laboratory; 1984.

[8] Yang JC, Cleary TG, Vázquez I, Boyer CI, King MD, Breuel BD, Gmurczyk G. Optimization of system discharge. In: Fire suppression system performance of alternative agents in aircraft engine and dry bay laboratory simulations, NIST SP-890, Washington DC, 1995. pp 407-782.

[9] Yang JC, Cleary TG, Huber ML, Grosshandler WL. Vapour nucleation in a cryogenic- fluiddissolved-nitrogen mixture during rapid depressurization. The Royal Society. 1999; 455: $1717-1738$.

[10]Blander M, Katz JL. Bubble nucleation in liquids. AIChE J. 1975; 21(5): 833-848.

[11]Forest TW, Ward CA. Homogeneous nucleation of bubbles in solutions at pressures above the vapor pressure of the pure liquid. J Chem Phys. 1978; 69(5): 2221-2230.

[12] Schmelzer WP, Baidakov G, Boltachev S. Kinetics of boiling in binary liquid-gas solutions: 
comparison of different approaches. J Chem Phys.2003; 119(12): 6166-6183.

[13] Němec T. Homogeneous bubble nucleation in binary systems of liquid solvent and dissolved gas. Chem Phys. 2016; 467: 26-37.

[14] Jiang W, Bian J, Liu Y, Gao S, Chen M, Du S. Modification of the $\mathrm{CO}_{2}$ surface tension calculation model under low-temperature and high-pressure condition. J Dispersion Sci Technol. 2017; 38(5): 671-676.

[15]Duan Y, Zhang C, Lin H, Zhu M. The prediction of surface tension for HFCs and HCFCs. J Eng Thermophys. 2001; 22(3): 278-280 (in Chinese).

[16] Nicola GD, Moglie M. A generalized equation for the surface tension of refrigerants. International Journal of Refrigeration. 2011; 34(4): 1098-1108.

[17] Nicola GD, Nicola CD, Moglie M. A new surface tension equation for refrigerants. Int J Thermophys. 2013; 34(12): 2243-2260.

[18]Zhu J, Duan Y, Yang Z, Lin H. Factors influencing the surface tension of binary hydrocarbon mixtures. Fuel. 2014; 116(1):116-122.

[19]Duan W, Zhao X, Zeng X, Liu Y. Surface tension of HFC-161 and compressor oil mixtures. International Journal of Refrigeration. 2018; 85: 191-199.

[20] Carey BS, Scriven LE, Davis HT. Semiempirical theory of surface tensions of pure normal alkanes and alcohols. AIChE J. 1978; 24(6): 1076-1080.

[21]Liang X, Michelsen ML, Kontogeorgis GM. A density gradient theory based method for surface tension calculations. Fluid Phase Equilib. 2016; 428: 153-163.

[22] Mu X, Frank F, Alpak FO, Chapman WG. Stabilized density gradient theory algorithm for modeling interfacial properties of pure and mixed systems. Fluid Phase Equilib. 2017; 435: $118-130$

[23] Wang P. Application of green surfactants developing environment friendly foam extinguishing agent. Fire Technol. 2015; 51(3): 503-511.

[24]Baidakov VG, Khotienkova MN, Andbaeva VN, Kaverin AM. Capillary constant and surface tension of methane-nitrogen solutions: 1. Experiment. Fluid Phase Equilib. 2011; 301(1): 67-72.

[25] Baidakov VG, Kaverin AM, Khotienkova MN, Andbaeva VN. Surface tension of an ethanenitrogen solution. 1: Experiment and thermodynamic analysis of the results. Fluid Phase 
Equilib. 2012; 328(35): 13-20.

[26] Baidakov VG, Kaverin AM, Khotienkova MN. Surface tension of ethane-methane solutions: 1. Experiment and thermodynamic analysis of the results. Fluid Phase Equilib. 2013; 356(10): 90-95.

[27] Dinenno PJ, Hanauska CP, Forssell EW. Design and engineering aspects of halon replacements. Process Saf Prog. 1995; 14(1): 57-62.

[28] Yang JC, Pitts WM, Breuel BD, Grosshandler WL, Cleveland WG. Rapid discharge of a fire suppressing agent. Int Commun Heat Mass Transf. 1996; 23(23): 835-844.

[29]Lemmon EW, Jacobsen RT. A generalized model for the thermodynamic properties of mixtures. Int J Thermophys. 1999; 20(3): 825-835.

[30]Lemmon EW, Jacobsen RT. Thermodynamic properties of mixtures of R-32, R-125, R-134a, and R-152a. Int J Thermophys. 1999; 20(6): 1629-1638.

[31]He MG, Yang YJ, Zhang Y, Zhang XX. Theoretical estimation of the isobaric heat capacity $c_{\mathrm{p}}$ of refrigerant. Appl Therm Eng. 2008; 28(14): 1813-1825.

[32] Hu YQ, Li ZB, Lu JF, Li YG, Jin Y. Surface tension calculation of liquid mixtures by PR EOS. Chem Eng (in Chinese). 1997; 25(3): 42-45.

[33]Peng DY, Robinson DB. A new two-constant equation of state. Industrial and Engineering Chemistry Fundamentals. 1976; 15(1): 92-94.

[34]Chen M, Xie Y, Wu H, Shi S, Yu J. Modeling solubility of nitrogen in clean fire extinguishing agent by Peng-Robinson equation of state and a correlation of Henry's law constants. Appl Therm Eng. 2016; 110: 457-468.

[35] Holden BS, Katz JL. The homogeneous nucleation of bubbles in superheated binary liquid mixtures. AIChE J. 1978; 24(2): 260-267.

[36] Lepori L, Gianni P, Matteoli E. Thermodynamic study of tetrachloromethane or heptane + cycloalkane mixtures. J Therm Anal Calorim. 2016; 124: 1497-1509.

[37] Matteoli E, Lepori L, Porcedda S. Thermodynamic study of mixtures containing dibromomethane. J Therm Anal Calorim. 2018; 132: 611-621.

[38] Chen M, Xie Y, Guo X, Yu J, Ma W. Predicting filling mass of nitrogen in fire agent bottle based on Peng-Robinson equation of state with Wong-Sandler mixing rule. Journal of Beijing University of Aeronautics and Astronautics (in Chinese). 2016; 42(10): 2162-2167. 
661 [39] Simoiu L, Trandafir I, Popescu G. New Thermodynamic Consistency Test for Isobaric 662 Vapour-Liquid Equilibrium Data. J Therm Anal Calorim. 1998; 52: 1023-1035. 